Feteris, E., H. Kloosterhuis, J. Plug, and C. Smith, Legal Argumentation and the Rule of Law, Eleven, the Hague, 2016, 230 pp. (incl. index), ISBN 978-94-6236-702-9.

Legal Argumentation and the Rule of Law is a collection of essays originally presented and discussed at the international conference "Legal Argumentation and the Rule of Law" organised at the Erasmus University of Rotterdam on 26 June 2015. The broad topic unifying the contributions contained in the volume edited by E. Feteris, H. Kloosterhuis, J. Plug, and C. Smith concerns the persistent tension between the encompassing idea of the "rule of law", which is traditionally considered a fundamental legal value, and the widely recognised role that legal reasoning, in turn mainly understood as the set of nonmechanical, or entirely-rule-constrained, forms of deliberation, plays in determining contents and validity of the law.

In brief the tension, which can take different shapes within a legal system, can be summarised as follows. On the one hand, the law is largely claimed to consist of rules. And rules are standards that can be, and in fact typically are, followed, without thinking about it, namely, without recourse to interpretation, argumentation, deliberation, justification, or akin processes of thought. On the other hand, there is wide recognition that reasoning is pervasive in law, since practically any stage of what is ordinarily considered the legal domain involves recourse to reasoning - the law, in other words, as an "arguable character", as the editors of the collection observes (p. 1). As a result, it is hardly deniable that legal reasoning too (and not just rules) contributes significantly to shaping the contents, structures and boundaries of legal orders. On this view, reasoning is no less central to the meaning and nature of law than are the general and abstract rules making up a legal order. And now one may wonder whether the law is best conceived in terms of rules and other standards the contents of which can be established without recourse to deliberative activities - this is the key idea underpinning the ideal of the "rule of law" - or rather the law is best characterised as an argumentative social practice and so a dynamic articulation of defeasible reasons, or process, only partly institutionalised, aimed at finding a right solution to the case at hand and seeking justice, not only control, predictability and certainty.

The contributors to this volume provide different insights into the above mentioned tension and the possible ways of arriving at a reconciliation of two principles - rule of law and arguable character of the law-potentially pulling into opposite directions. In consideration of the space limitation, here it is not possible to summarise either the rich 
variety of views insightfully defended in the essays collected in this volume or the diversity of approaches and styles used to explore the basic legal tension between rule of law and arguable character of the law. Two points are, however, worthy being noted before concluding with the recommendation that the book deserves careful reading and should be considered an essential reference for anyone who has a theoretical interest in legal studies.

First, most of the contributors to the volume seems to be convinced that a reconciliation of some kind is not only possible but indeed necessary between rule of law and arguable character of the law. Indeed, an underlying theme explored in the book is the idea that the rule of law is implemented not only in the law-making processes, as they take place in Parliaments and, more broadly, in legislative institutions, but also in the activities through which the general and abstract norms of the law are understood, interpreted, applied and justified. And insofar as this is the case-namely, insofar as the rule of law itself is a (partly) procedural ideal that unfolds in the territory of legal decision-making and interpretation - it can reasonably be concluded that the task of operating a reconciliation between rule of law and arguable character of the law should be entrusted to the theory of rational argumentation. Hence not only the importance of theorising a sound account of legal reasoning qua rational argumentation but also its centrality in the legal domain and studies.

The second point that should be made is that the essays contained in this volume reflect the vast array of theoretical interests and philosophical backgrounds of their authors. Some of the texts collated in the volume originally contribute to (what is known by the name of) general jurisprudence. By "general jurisprudence", it is traditionally meant the theoretical study of the concepts, principles, notions and distinctions common to all legal systems, or at least to those legal orders of comparable degree of maturity and development. In the volume under review, contributions to this field of studies can be found, for instance, in the works of Matthias Klatt, Damiano Canale and Giovanni Tuzet, Bart van Klink, Harm Kloosterhuis and Carel Smith, Maurizio Manzin, Daniel Oliver-Lalana, Federico Puppo, Eric Tjong Tjin Tai, and Frank Zenker and Christian Dahlman. Other texts are, instead, conceived as studies of the so-called "particular jurisprudence". Namely, they are concerned with the theoretical understanding of a specific system of laws, or even of a given legal branch within a certain jurisdiction. Exemplary in this respect are the contributions of Richard Gaskins, Paul van den Hoven, Hendrik Kaptein, Anne Ruth Mackor, Antoinette Muntjewerff and Kirsten van Loo, Marko Novak (who, however, also 
deals with issues of pertinence of general jurisprudence), and José Plug. Finally, the volume contains contributions from argumentation theory, which is originally explored in particular in the works of Eveline Feteris and Jean Wagemans. The choice of scrutinizing the claim that some form of reconciliation between the principle of the rule of law and the arguable character of law is needed from such diverse perspectives of analysis and different theoretical approaches adds to the originality of the book and is a further reason why this work should be carefully read by legal scholars and practical philosophers with an interest in the study of the law.

\section{Stefano Bertea}

